\title{
Salário mínimo, benefício previdenciário e as famílias de baixa renda*
}

\author{
Cláudio Salvadori Dedecca** \\ Eliane Navarro Rosandiski ${ }^{\star \star \star}$ \\ Carolina Veríssimo Barbieri ${ }^{\star \star \star \star}$ \\ Adriana Jungbluth ${ }^{\star \star * \star *}$
}

\begin{abstract}
Este artigo tem foco nas famílias com rendimento per capita de até $1 / 4$ do salário mínimo. São analisadas as condições de inserção no mercado de trabalho e a influência dos benefícios previdenciários para o padrão de renda auferido. A preocupação, portanto, volta-se para a importância dos benefícios da previdência, no sentido de atenuar a fragilidade de renda destas famílias e as conseqüências da desvinculação do valor do seu piso do salário mínimo para este padrão de rendimentos. Analisando-se as características dos componentes das famílias de baixa renda, observa-se que, diante das transformações estruturais no processo de produção e do cenário conjuntural da economia brasileira, aqueles com idade ativa não apresentam os pré-requisitos necessários para se inserirem de forma digna no mundo do trabalho. Dessa forma, o estudo da composição da renda das famílias mais pobres mostra que a renda dos inativos - aposentados e pensionistas - é fundamental para retirar tais famílias do limite da linha de pobreza. O perfil dos componentes das famílias será analisado a partir dos microdados da Pesquisa Nacional por Amostra de Domicílios - PNAD/IBGE - para 2004, segundo idade, nível de escolaridade, cor ou raça e inserção no mercado de trabalho propriamente dita: tipo de atividade exercida e posição na ocupação. A comparação do perfil dos componentes das famílias mais carentes com o do total das famílias mostrará que as rendas de aposentadoria e pensão tornam-se fundamentais não apenas para diminuição da desigualdade, mas, fundamentalmente, para redução da pobreza.
\end{abstract}

Palavras-chave: Salário mínimo. Previdência. Famílias de baixa renda. Transferência de renda.

\section{Introdução}

Este ensaio analisa as condições de renda das famílias de baixa renda. O critério adotado é aquele inscrito na Lei no 8.742/
93, que considera famílias de baixa renda aquelas que auferem rendimento per capita de até $1 / 4$ do salário mínimo.

A análise procura explicitar a determinação do mercado de trabalho para a baixa

\footnotetext{
"Trabalho apresentado no XV Encontro Nacional de Estudos Populacionais, da Abep, realizado em Caxambu - MG, de 18 a 22 de setembro de 2006

${ }^{\star *}$ Professor Doutor do IE/Unicamp e pesquisador do Cesit- IE/Unicamp.

*** Professora Doutora da PUC-Campinas e pesquisadora do Cesit- IE/Unicamp.

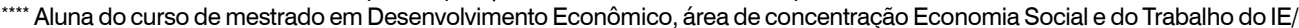
Unicamp.

${ }_{\star \star \star \star \star \star}^{*}$ Aluna de graduação do IE/Unicamp e auxiliar de pesquisa do Cesit- IE/Unicamp.
} 
renda e a influência do rendimento previdenciário para sua atenuação. Busca-se responder, em primeiro lugar, se a baixa renda destas famílias decorre da não inserção econômica no mercado de trabalho e, em segundo lugar, se o benefício previdenciário tem papel importante na renda destas famílias.

Este exercício evidencia o papel do salário mínimo para as famílias de baixa renda, bem como indica possíveis implicações da desvinculação do piso previdenciário do salário mínimo para o padrão de rendimento dessas famílias.

O artigo está dividido em quatro partes, além desta introdução. A primeira apresenta um quadro geral das condições de inserção no mundo do trabalho, apontando algumas características da década de 90 e dos anos 2000. A segunda trata das características gerais das famílias de baixa renda. Em seguida, são apontados meios alternativos de sobrevivência dessas famílias, destacando o papel da previdência social. Por fim, são apresentadas algumas considerações sobre as relações entre o padrão de rendimentos das famílias de baixa renda, o mercado de trabalho, o benefício previdenciário e o salário mínimo, com o objetivo de contribuir para o debate sobre as estratégias de políticas de renda para estas famílias.

\section{Quadro geral das condições de inserção no mundo do trabalho}

Na década de 90 , a adoção das políticas de abertura comercial e financeira mudou o padrão de absorção da população economicamente ativa (PEA). Neste novo padrão, houve redução acentuada da oferta de novos postos de trabalho que, diante do crescimento da PEA, alimentou uma ten- dência recorrente de elevação da taxa de desemprego (Tabela 1).

A redução da oferta de postos de trabaIho pode ser entendida como resultado dos processos de racionalização produtiva e administrativa empreendidos pelas empresas, enquanto estratégia de sobrevivência em uma economia de baixo crescimento e fortemente exposta a uma concorrência externa. $\mathrm{O}$ baixo desempenho econômico afetou, ademais, a evolução das receitas públicas, obrigando os governos a racionalizarem também suas atividades, contendo, dentro de certos limites, o aumento do emprego público. Também a estratégia da política econômica foi associada à privatização de parte importante do setor produtivo estatal, que exigiu a redução de seu nível de emprego.

Dois outros processos ainda reiteraram a perda de capacidade de gera-ção de novos postos de trabalho: a queda da taxa de inflação, induzindo alterações nas estratégias das instituições financeiras, que reduziram fortemente seu volume de empregos; e a concorrência externa, que, em um contexto de valorização cambial, exigiu um reordenamento do setor agrícola com destruição ponderável de postos de trabalho nesse setor.

Do ponto de vista do mercado de trabaIho, a menor oferta de ocupações traduziuse em mudança dos processos seletivos de contratação adotados pelas empresas. A oferta abundante de mão-de-obra requereu, inclusive, que as empresas adotassem estratégias de recrutamento que reduzissem os custos do processo de seleção. Um dos mecanismos utilizados foi a exigência de escolaridade mínima, mesmo que os postos de trabalho não requisitassem tal qualificação na execução das tarefas. Ao

TABELA 1

Taxas de participação, ocupacão e desemprego Brasil-1992-2004

\begin{tabular}{lccc}
\multicolumn{1}{c}{ Taxas } & $\mathbf{1 9 9 2}$ & $\mathbf{1 9 9 8}$ & $\mathbf{2 0 0 4}$ \\
\hline Taxa de participação & 58,0 & 57,0 & 59,0 \\
Taxa de ocupação & 93,0 & 90,0 & 90,0 \\
Taxa de desemprego & 7,0 & 10,0 & 10,0 \\
\hline
\end{tabular}

Fonte: IBGE. Pesquisa Nacional por Amostra de Domicílios - PNAD. Elaboração dos autores. 
demandarem escolaridade mínima, as empresas reduziam (e ainda reduzem) a fila de postulantes aos postos ofertados, monitorando os custos incorridos com o processo de contratação. Quando se analisa o perfil da mão-de-obra segundo escolaridade, percebe-se que o maior grau de instrução tem passado a ser um requisito progressivamente relevante no recrutamento de pessoas no mercado de trabalho (Tabela 2).

Um dos efeitos deste processo de reordenamento do mercado de trabalho foi, como aponta Baltar (2005), uma mudança radical na composição da ocupação com diminuição da participação dos jovens e redução do emprego nas grandes empresas. No que se refere à posição na ocupação, o reordenamento alimentou um aumento expressivo dos empregados sem carteira de trabalho assinada e do trabalho autônomo. Tal movimento, entretanto, começou a ser parcialmente revertido em 2004, com a expansão do emprego com carteira assinada.

As novas condições de inserção no mercado de trabalho, ainda segundo Baltar (2005), associaram-se a transformações na estrutura de remunerações. Observou-se uma ampliação acentuada de ocupados nas faixas de remunerações mais baixas. Houve aumento significativo na proporção de pessoas ganhando menos de três salários mínimos, sendo que quase três quartos do total de ocupados, em 2003, tinham remuneração inferior a um salário mínimo.

Essa aproximação da estrutura de remuneração ao redor do salário mínimo tem estimulado o debate do papel da política de salário mínimo na economia. De um lado, pode-se argumentar que o salário mínimo tem a função de sustentar os rendimentos de base no mercado de trabalho e reduzir as desigualdades. De outro, a existência de inserções não formais no mercado de trabalho diminui o efeito da política de valorização do salário mínimo sobre o total das pessoas ocupadas. Neste sentido, seria importante que a política fosse acompanhada de outros instrumentos que elevassem o grau de cobertura da regulação pública sobre o mercado de trabalho.

Também é fundamental considerar os impactos da política de valorização do salário mínimo sobre aquelas de proteção social, mais especificamente nas políticas de transferência de renda, como aposentadorias e pensões, tanto em relação ao gasto como à receita.

Há razoável convergência de que essas políticas contribuem para atenuar a pobreza no país, devido à sua efetividade para as famílias de baixa renda. Espera-se, inclusive, que as pessoas mais carentes sejam as mais beneficiadas por uma política de valorização do salário mínimo, devido ao seu maior impacto sobre os benefícios sociais de menor valor.

Apesar de não analisar a importância da política de valorização do salário mínimo para as políticas de transferência de renda e suas relações com a questão distributiva, este trabalho procura evidenciar a relevância de tais políticas para a sobrevivência das famílias de baixa renda, por afetarem significativamente os níveis de rendimentos desta população.

\section{Características gerais das famílias de baixa renda}

Antes de apresentar as características das famílias de baixa renda, faz-se

TABELA2

Distribuição dos ocupados, segundo nível de escolaridade Brasil-1992-2004

\begin{tabular}{lcrr} 
& Brasil - 1992-2004 & Em porcentagem \\
\hline \multicolumn{1}{c}{ Nível de escolaridade } & $\mathbf{1 9 9 2}$ & $\mathbf{1 9 9 8}$ & $\mathbf{2 0 0 4}$ \\
\hline Total & $\mathbf{1 0 0 , 0}$ & $\mathbf{1 0 0 , 0}$ & $\mathbf{1 0 0 , 0}$ \\
Sem instrução & 17,0 & 12,0 & 9,0 \\
Ensino fundamental incompleto & 51,0 & 47,0 & 38,0 \\
Ensino fundamental completo & 8,0 & 9,0 & 10,0 \\
Ensino médio completo (1) & 15,0 & 21,0 & 30,0 \\
Ensino superior & 9,0 & 11,0 & 13,0 \\
\hline
\end{tabular}

Fonte: IBGE. Pesquisa Nacional por Amostra de Domicílios - PNAD. Elaboração dos autores.

(1) Inclui as pessoas com ensino médio incompleto. 
necessário definir quem são essas famílias. Em geral, o primeiro passo para identificálas é determinar uma linha de pobreza. Segundo Barbieri (2003), as linhas nacionais de pobreza variam, fundamentalmente, de acordo com o perfil da população e a estrutura de renda de cada país. No Brasil, o atual governo adotou uma linha de pobreza que orientou a implementação de sua principal política pública de cunho social o Programa Fome Zero -, que definiu a renda familiar per capita de $\mathrm{R} \$ 71,53$ ao mês. Em 2004, o governo reordenou as políticas de transferência de renda, consolidando-as no Programa Bolsa-Família. O Fome Zero foi mantido enquanto um conjunto amplo de políticas de renda, produção e consumo.

A Lei $n$ o 8.742/93 definiu como família carente - o que se pode conceituar também como família de baixa renda - aquela cuja renda mensal per capita é inferior a $1 / 4$ do salário mínimo. Entretanto, defende-se que a renda per capita utilizada para definir tais famílias deveria ser de um salário mínimo, o que explica a limitada recorrência do valor legal (ANFIP, 1995, p. 75-76).
Tendo em vista que o foco deste artigo não é discutir a linha de pobreza propriamente dita, mas sim apresentar as características das famílias de baixa renda, consideram-se aqui aquelas cuja renda total mensal era de até $R \$ 260,00$ em 2004, ou seja, possuíam um poder de compra total equivalente a um salário mínimo. Como as famílias de baixa renda, analisadas neste texto, tinham em 2004 uma média de quatro componentes, seu rendimento per capita correspondente àquele determinado na Lei anteriormente citada.

As características dessas famílias, bem como sua evolução no período de 1995 a 2004 , foram obtidas a partir dos microdados da PNAD, que podem dar evidências das possíveis alternativas que elas possuem para sobreviver. As Tabelas 3 e 4 apresentam a distribuição das famílias por região geográfica no período em questão.

No Brasil, em 1995, existiam pouco mais de 39 milhões de famílias, chegando a quase 53 milhões em 2004.

A distribuição espacial do total de famílias se modificou entre 1995 e 2004, de modo que ampliou a participação relativa do

TABELA 3

Distribuição das famílias e média de pessoas, por faixa de renda familiar, segundo regiões Brasil-1995

\begin{tabular}{|c|c|c|c|c|c|c|}
\hline \multirow[b]{2}{*}{ Regiōes } & \multicolumn{3}{|c|}{ Renda familiar maior que zero } & \multicolumn{3}{|c|}{$\begin{array}{c}\text { Renda familiar per capita até um } \\
\text { salário mínimo }\end{array}$} \\
\hline & Pessoas (\%) & Famílias (\%) & $\begin{array}{c}\text { Média de } \\
\text { pessoas na } \\
\text { família }\end{array}$ & Pessoas (\%) & Famílias (\%) & $\begin{array}{c}\text { Média de } \\
\text { pessoas na } \\
\text { família }\end{array}$ \\
\hline Brasil & 100,0 & 100,0 & 4 & 100,0 & 100,0 & 4 \\
\hline Norte & 4,8 & 4,2 & 4 & 5,5 & 4,9 & 5 \\
\hline Nordeste & 28,8 & 26,3 & 4 & 43,0 & 40,8 & 4 \\
\hline Sudeste & 44,0 & 46,0 & 3 & 31,9 & 33,5 & 4 \\
\hline Sul & 15,6 & 16,6 & 3 & 12,8 & 13,6 & 4 \\
\hline Centro-Oeste & 6,9 & 6,9 & 4 & 6,8 & 7,1 & 4 \\
\hline
\end{tabular}

(continuação)

\begin{tabular}{lccc}
\hline & \multicolumn{3}{c}{ Renda familiar até um salário mínimo } \\
\cline { 2 - 4 } Regióes & Pessoas (\%) & Famílias (\%) & $\begin{array}{c}\text { Média de } \\
\text { pessoas na } \\
\text { família }\end{array}$ \\
\hline Brasil & 100,0 & 100,0 & 3 \\
Norte & 4,2 & 3,9 & 3 \\
Nordeste & 55,5 & 50,4 & 3 \\
Sudeste & 24,3 & 28,3 & 3 \\
Sul & 10,2 & 11,3 & 3 \\
Centro-Oeste & 5,9 & 6,2 & 3 \\
\hline
\end{tabular}

Fonte: IBGE. Pesquisa Nacional por Amostra de Domicílios - PNAD. Elaboração dos autores. 
TABELA 4

Distribuição das famílias e média de pessoas, por faixa de renda familiar, segundo regiões Brasil - 2004

\begin{tabular}{|c|c|c|c|c|c|c|}
\hline \multirow[b]{2}{*}{ Regiões } & \multicolumn{3}{|c|}{ Renda familiar maior que zero } & \multicolumn{3}{|c|}{$\begin{array}{l}\text { Renda familiar per capita até um } \\
\text { salário mínimo }\end{array}$} \\
\hline & Pessoas (\%) & Famílias (\%) & $\begin{array}{c}\text { Média de } \\
\text { pessoas na } \\
\text { família }\end{array}$ & Pessoas (\%) & Famílias (\%) & $\begin{array}{c}\text { Média de } \\
\text { pessoas na } \\
\text { família }\end{array}$ \\
\hline Brasil & 100,0 & 100,0 & 4 & 100,0 & 100,0 & 4 \\
\hline Norte & 7,9 & 7,1 & 4 & 9,7 & 9,0 & 5 \\
\hline Nordeste & 27,7 & 25,8 & 4 & 37,9 & 37,1 & 5 \\
\hline Sudeste & 42,2 & 43,8 & 4 & 34,4 & 35,3 & 4 \\
\hline Sul & 15,0 & 15,9 & 4 & 11,3 & 11,7 & 4 \\
\hline Centro-Oeste & 7,1 & 7,3 & 4 & 6,7 & 6,8 & 4 \\
\hline
\end{tabular}

\begin{tabular}{lccc}
\hline Regiões & & Renda familiar até um salário mínimo & \\
\cline { 2 - 4 } & Pessoas (\%) & Famílias (\%) & $\begin{array}{c}\text { Média de } \\
\text { pessoas na } \\
\text { família }\end{array}$ \\
\hline Brasil & & & 4 \\
Norte & 100,0 & 100,0 & 4 \\
Nordeste & 9,5 & 8,6 & 4 \\
Sudeste & 55,4 & 50,4 & 3 \\
Sul & 22,9 & 26,9 & 3 \\
Centro-Oeste & 7,7 & 8,7 & 3 \\
\hline
\end{tabular}

Fonte: IBGE. Pesquisa Nacional por Amostra de Domicílios - PNAD. Elaboração dos autores.

TABELA 5

Distribuição de pessoas e famílias, por faixa de renda familiar, segundo regiões Brasil - 2004

\begin{tabular}{|c|c|c|c|c|c|}
\hline \multirow{3}{*}{ Região Geográfica } & & \multirow{3}{*}{$\begin{array}{c}\text { Em porcentagem } \\
\text { Total }\end{array}$} \\
\hline & \multicolumn{2}{|c|}{$\begin{array}{c}\text { Renda familiar per capita até } \\
\text { um salário mínimo }\end{array}$} & \multicolumn{2}{|c|}{$\begin{array}{l}\text { Renda familiar até um } \\
\text { salário mínimo }\end{array}$} & \\
\hline & Pessoas & Famílias & Pessoas & Famílias & \\
\hline Brasil & 58,6 & 52,1 & 12,3 & 14,0 & 100,0 \\
\hline Norte & 71,8 & 65,3 & 14,6 & 16,9 & 100,0 \\
\hline Nordeste & 80,3 & 75,0 & 24,6 & 27,4 & 100,0 \\
\hline Sudeste & 47,8 & 42,0 & 6,7 & 8,6 & 100,0 \\
\hline Sul & 44,0 & 38,4 & 6,3 & 7,7 & 100,0 \\
\hline Centro-Oeste & 54,6 & 48,9 & 7,9 & 10,2 & 100,0 \\
\hline
\end{tabular}

Fonte: IBGE. Pesquisa Nacional por Amostra de Domicílios - PNAD. Elaboração dos autores.

Norte ao mesmo tempo em que diminuiu a do Sudeste e, em menor intensidade, a do Nordeste. Seguindo a tendência geral, as famílias de baixa renda tiveram sua participação relativa ampliada no Norte. Contudo, é interessante destacar que, apesar de o Sul não ter perdido participação relativa no total de famílias, o percentual de famílias pobres nesta região reduziu-se de forma significativa. As demais regiões mantiveram as mesmas proporções entre o total de famílias e as de baixa renda no período em questão.
Complementando a análise regional, os dados da distribuição das famílias segundo a renda familiar, em 2004, mostram que, no Nordeste, a participação daquelas com renda de até um salário mínimo ultrapassava $27 \%$, enquanto as com renda familiar per capita de até um salário mínimo chegavam a $75 \%$ do total de famílias da região (Tabela 5). O Norte apresentava o segundo pior perfil de renda familiar. Nas demais regiões as proporções ficavam abaixo da média nacional, com destaque para a Região Sul, onde apenas $7,7 \%$ das famílias 
apresentavam renda familiar abaixo de um salário mínimo.

Uma vez conhecida a extensão da presença de tais famílias, a questão a ser abordada diz respeito à sobrevivência das pessoas que as compõem. Para isto, é necessário fazer sua caracterização socioeconômica.

Iniciando com os indicadores gerais de mercado de trabalho, observa-se que a taxa de participação apenas ampliou-se para o total de famílias. No entanto, o mercado de trabalho se revelou pouco favorável para absorver os indivíduos das famílias de baixa renda, visto que a taxa de participação, entre 1995 e 2004, diminuiu de 52,5\% para $49,7 \%$ no caso daquelas com renda familiar de até um salário mínimo. Essa baixa capacidade de absorção pode ser evidenciada quando se constata que a taxa de desemprego, no período, subiu de $8,5 \%$ para $18,3 \%$ da PEA - percentual consideravelmente superior ao observado para o total da economia (Tabelas 6 e 7).
Pela construção metodológica das informações que estão sendo analisadas, é de se esperar uma menor taxa de ocupação para as famílias de baixa renda e, justamente por isso, elas se encontram nessa situação. Entretanto, o argumento a ser sublinhado é que o baixo dinamismo da economia afetou negativamente os indicadores de participação dessas famílias.

Felizmente, a renda dessas famílias não se restringe àquelas provenientes do trabalho, sendo complementada por outros tipos de rendimentos, em especial as pensões e aposentadorias.

Os dados sintetizados nas Tabelas 8 e 9 mostram de que maneira tais rendimentos contribuem para a sobrevivência destas famílias.

O movimento a ser destacado entre 1995 e 2004, para as famílias de baixa renda, corresponde à menor participação dos ocupados e a uma ampliação da participação da renda previdenciária no conjunto de inativos e desempregados. Tal

TABELA 6

Taxas de participação, ocupação e desemprego, por faixa de renda familiar Brasil-1995

\begin{tabular}{lccc}
\hline \multicolumn{1}{c}{ Taxas } & $\begin{array}{c}\text { Renda familiar } \\
\text { maior que zero }\end{array}$ & $\begin{array}{c}\text { Renda familiar per capita } \\
\text { até um salário mínimo }\end{array}$ & $\begin{array}{c}\text { Em ponda familiar até } \\
\text { um salário mínimo }\end{array}$ \\
\hline Taxa de participação & 58,1 & 55,0 & 52,5 \\
Taxa de ocupação & 94,5 & 92,9 & 91,5 \\
Taxa de desemprego & 5,5 & 7,1 & 8,5 \\
\hline
\end{tabular}

Fonte: IBGE. Pesquisa Nacional por Amostra de Domicílios - PNAD. Elaboração dos autores.

TABELA 7

Taxas de participação, ocupação e desemprego, por faixa de renda familiar Brasil-2004

\begin{tabular}{lccc}
\multicolumn{1}{c}{ Taxas } & $\begin{array}{c}\text { Renda familiar } \\
\text { maior que zero }\end{array}$ & $\begin{array}{c}\text { Renda familiar per capita } \\
\text { até um salário mínimo }\end{array}$ & $\begin{array}{c}\text { Em ponda familiar até } \\
\text { um salário mínimo }\end{array}$ \\
\hline Taxa de participação & 59,4 & 54,4 & 49,7 \\
Taxa de ocupação & 91,2 & 87,5 & 81,7 \\
Taxa de desemprego & 8,8 & 12,5 & 18,3 \\
\hline
\end{tabular}

Fonte: IBGE. Pesquisa Nacional por Amostra de Domicílios - PNAD. Elaboração dos autores.

TABELA 8

Proporção de pessoas que recebem renda previdenciária, por faixa de renda familiar, segundo condição de atividade Brasil - 1995

\begin{tabular}{|c|c|c|c|}
\hline \multicolumn{3}{|c|}{ Brasil - 1995} & \multirow{2}{*}{$\begin{array}{l}\text { Em porcentagem } \\
\text { Renda familiar até } \\
\text { um salário mínimo }\end{array}$} \\
\hline Condição de atividade & $\begin{array}{l}\text { Renda familiar } \\
\text { maior que zero }\end{array}$ & $\begin{array}{l}\text { Renda familiar per capita } \\
\text { até um salário mínimo }\end{array}$ & \\
\hline Total & 10,2 & 7,9 & 8,8 \\
\hline Inativos & 16,9 & 13,3 & 17,4 \\
\hline Ocupados & 6,2 & 4,3 & 2,2 \\
\hline Desempregados & 3,3 & 2,6 & 4,4 \\
\hline
\end{tabular}

Fonte: IBGE. Pesquisa Nacional por Amostra de Domicílios - PNAD. Elaboração dos autores. 
TABELA 9

Proporção de pessoas que recebem renda previdenciária, por faixa de renda familiar, segundo condição de atividade Brasil - 2004

\begin{tabular}{lccc} 
Condição de atividade & $\begin{array}{c}\text { Renda familiar } \\
\text { maior que zero }\end{array}$ & $\begin{array}{c}\text { Renda familiar per capita } \\
\text { até um salário mínimo }\end{array}$ & $\begin{array}{c}\text { Em porcentagem } \\
\text { um salário mínimo }\end{array}$ \\
\hline Total & $\mathbf{1 2 , 5}$ & $\mathbf{8 , 8}$ & $\mathbf{9 , 0}$ \\
Inativos & 26,6 & 19,3 & 22,0 \\
Ocupados & 7,3 & 4,5 & 1,2 \\
Desempregados & 6,6 & 6,0 & 9,0 \\
\hline
\end{tabular}

Fonte: IBGE. Pesquisa Nacional por Amostra de Domicílios - PNAD. Elaboração dos autores.

informação complementa os dados disponibilizados sobre indicadores de mercado de trabalho, em que, provavelmente, o aumento do desemprego está associado ao indivíduo que recebe algum benefício previdenciário, mas ainda assim continua procurando uma vaga no mercado de trabalho, com objetivo de ampliar a renda familiar.

Um outro argumento a ser abordado diz respeito ao fato de os baixos rendimentos dos ocupados dessas famílias estarem associados a uma inserção pouco favorável no mercado de trabalho.

Dessa forma, percebe-se que, apesar de o percentual de indivíduos que recebiam estas rendas ser menor nas famílias de baixa renda do que no total de famílias, sua importância para sobrevivência das primeiras era decisiva.

A questão que se coloca a partir dessa constatação é entender porquê tais famílias dependem tanto da renda de pensão ou aposentadoria. Em geral, argumenta-se que tais rendas representariam um desestímulo ao trabalho, visto que possibilitariam a reprodução dos membros da família sem que a remuneração decorresse de uma atividade produtiva. No entanto, este argumento não encontra respaldo nas taxas de desemprego observadas.

$\mathrm{Na}$ verdade, as causas das taxas de ocupação mais reduzidas nestas famílias podiam ser encontradas no perfil dos membros em idade ativa que estão inseridos no mercado de trabalho. Segundo os dados de 2004, tais pessoas eram fundamentalmente pardas e negras $(60 \%$ e $8 \%$, respectivamente) e aproximadamente $80 \%$ delas não possuíam o ensino fundamental completo, enquanto o percentual com superior não chegava a $1 \%$. Os ramos de atividade em que tais pessoas se inseriam eram a agricultura, o serviço doméstico e o comércio e reparação.

Além disso, a forma de inserção destas pessoas deve ser considerada predominantemente precária, visto que o trabalho conta-própria sem contribuição previdenciária representava $40 \%$ de sua ocupação total, seguido pelo emprego sem carteira de trabalho assinada (32\%) e pelo emprego doméstico sem carteira de trabalho (15\%). Vale registrar que menos de $10 \%$ das pessoas ocupadas estavam inseridas em alguma atividade que regularizava 0 contrato de trabalho (Tabela 10).

Estes dados apontam dois fatos preocupantes. Em primeiro lugar, as formas de inserção predominantes entre estas famílias, em geral, estão associadas à baixíssima remuneração. A fragilidade da renda familiar não se associa à baixa inserção dos membros no mercado de trabalho, mas sim à baixíssima remuneração que estes auferem. As informações disponíveis confirmam que a média dos rendimentos deste perfil de inserção, nos ramos de atividade mencionados, ficava em torno de $\mathrm{R} \$ 150,00$, em 2004 , isto é, cerca de $60 \%$ do valor do salário mínimo vigente naquele ano. Em segundo lugar, o fato dessa inserção ser precária, inclusive do ponto de vista do nível de remuneração auferida, faz com que o trabalhador fique completamente à margem de qualquer espécie de proteção trabaIhista. Só quando ele atingir a idade mínima para se aposentar é que poderá contar com auxílio previdenciário de origem não contributiva.

Segundo os dados da Tabela 11, o perfil das pessoas que recebiam algum tipo de rendimento oriundo de pensão e 
TABELA 10

Distribuição das pessoas que recebem rendimento de trabalho, por faixa de renda familiar, segundo atributos pessoais e de inserção no mercado de trabalho

\begin{tabular}{|c|c|c|c|}
\hline \multicolumn{4}{|c|}{$\begin{array}{l}\text { pessoais e de inserçáo no mercado de trabalho } \\
\text { Brasil - } 2004\end{array}$} \\
\hline $\begin{array}{l}\text { Atributos pessoais e de } \\
\text { inserção no mercado de trabalho }\end{array}$ & $\begin{array}{l}\text { Renda familiar } \\
\text { maior que zero }\end{array}$ & $\begin{array}{l}\text { Renda familiar per capita } \\
\text { até um salário mínimo }\end{array}$ & $\begin{array}{l}\text { Renda familiar até } \\
\text { um salário mínimo }\end{array}$ \\
\hline \multicolumn{4}{|l|}{ Condição de atividade } \\
\hline Menores de dez anos & 0,0 & 0,0 & 0,0 \\
\hline Inativos & 0,0 & 0,0 & 0,0 \\
\hline Ocupados & 100,0 & 100,0 & 100,0 \\
\hline Desempregados & 0,0 & 0,0 & 0,0 \\
\hline \multicolumn{4}{|l|}{ Faixa de idade } \\
\hline 10 a 15 anos & 1,3 & 2,0 & 1,8 \\
\hline 16 a 17 anos & 2,4 & 3,2 & 2,5 \\
\hline 18 a 24 anos & 17,5 & 18,4 & 20,3 \\
\hline 25 a 39 anos & 40,1 & 42,6 & 43,0 \\
\hline 40 a 54 anos & 29,1 & 26,2 & 24,8 \\
\hline 55 a 64 anos & 7,3 & 6,0 & 7,0 \\
\hline 65 ou mais & 2,5 & 1,6 & 0,7 \\
\hline \multicolumn{4}{|l|}{ Nível de escolaridade } \\
\hline Sem instrução ou menos de um ano & 8,8 & 14,8 & 24,6 \\
\hline Ensino fundamental incompleto & 37,0 & 50,6 & 53,9 \\
\hline Ensino fundamental completo & 10,2 & 10,7 & 7,5 \\
\hline Ensino médio completo (1) & 29,9 & 21,5 & 12,9 \\
\hline Superior & 13,5 & 1,8 & 0,6 \\
\hline \multicolumn{4}{|l|}{ Cor } \\
\hline Branca & 53,5 & 39,1 & 30,4 \\
\hline Preta & 6,4 & 7,9 & 8,5 \\
\hline Parda & 39,5 & 52,6 & 60,7 \\
\hline Demais & 0,6 & 0,4 & 0,4 \\
\hline \multicolumn{4}{|l|}{ Sexo } \\
\hline Homens & 60,6 & 63,8 & 62,5 \\
\hline Mulheres & 39,4 & 36,2 & 37,5 \\
\hline \multicolumn{4}{|l|}{ Posição na ocupação } \\
\hline Empregados com carteira & 41,8 & 30,8 & 9,4 \\
\hline Empregados sem carteira & 20,6 & 26,7 & 32,0 \\
\hline Conta-própria com previdência & 3,4 & 1,4 & 0,8 \\
\hline Conta-própria sem previdência & 21,2 & 27,1 & 40,3 \\
\hline Empregadores com previdência & 2,6 & 0,3 & 0,1 \\
\hline Empregadores sem previdência & 2,0 & 1,1 & 0,6 \\
\hline Domésticos com carteira & 2,1 & 2,5 & 1,9 \\
\hline Domésticos sem carteira & 6,2 & 10,1 & 14,8 \\
\hline Trab. não-remunerados (mais de 15 horas) & 0,1 & 0,2 & 0,2 \\
\hline \multicolumn{4}{|l|}{ Ramo de atividade } \\
\hline Agrícola & 13,5 & 21,9 & 36,2 \\
\hline Outras atividades industriais & 0,9 & 0,7 & 0,3 \\
\hline Indústria de transformação & 15,4 & 13,5 & 8,3 \\
\hline Indústria da construção & 7,0 & 9,0 & 6,6 \\
\hline Comércio e reparação & 18,5 & 16,6 & 13,5 \\
\hline Alojamento e alimentação & 3,7 & 3,9 & 3,5 \\
\hline Transporte e comunicação social & 5,2 & 4,2 & 2,7 \\
\hline Administração pública & 5,6 & 3,5 & 2,0 \\
\hline Serviços sociais & 9,7 & 5,3 & 2,5 \\
\hline Serviço doméstico & 8,3 & 12,6 & 16,7 \\
\hline Outros serviços & 4,5 & 4,3 & 4,6 \\
\hline Outras atividades maldefinidas & 7,4 & 4,2 & 2,0 \\
\hline
\end{tabular}

Fonte: IBGE. Pesquisa Nacional por Amostra de Domicílios - PNAD. Elaboração dos autores.

(1) Inclui as pessoas com ensino médio incompleto. 
TABELA 11

Distribuição das pessoas que recebem rendimento de aposentadoria e pensão, por faixa de renda familiar, segundo atributos pessoais e de inserção no mercado de trabalho Brasil-2004 Em porcentagem

\begin{tabular}{|c|c|c|c|}
\hline $\begin{array}{c}\text { Atributos pessoais e de } \\
\text { inserção no mercado de trabalho }\end{array}$ & $\begin{array}{l}\text { Renda familiar } \\
\text { maior que zero }\end{array}$ & $\begin{array}{l}\text { Renda familiar per capita } \\
\text { até um salário mínimo }\end{array}$ & $\begin{array}{l}\text { Renda familiar até } \\
\text { um salário mínimo }\end{array}$ \\
\hline \multicolumn{4}{|l|}{ Condição de atividade } \\
\hline Menores de dez anos & 0,0 & 0,0 & 0,0 \\
\hline Inativos & 71,5 & 77,6 & 89,4 \\
\hline Ocupados & 26,2 & 18,9 & 4,0 \\
\hline Desempregados & 2,3 & 3,6 & 6,6 \\
\hline \multicolumn{4}{|l|}{ Faixa de idade } \\
\hline 10 a 15 anos & 1,1 & 1,3 & 1,0 \\
\hline 16 a 17 anos & 0,6 & 0,6 & 0,6 \\
\hline 18 a 24 anos & 2,2 & 3,0 & 5,2 \\
\hline 25 a 39 anos & 7,1 & 10,4 & 9,9 \\
\hline 40 a 54 anos & 16,0 & 13,2 & 9,2 \\
\hline 55 a 64 anos & 25,9 & 21,9 & 16,5 \\
\hline 65 ou mais & 47,1 & 49,6 & 57,5 \\
\hline \multicolumn{4}{|l|}{ Nível de escolaridade } \\
\hline Sem instrução ou menos de um ano & 28,6 & 45,4 & 46,5 \\
\hline Ensino fundamental incompleto & 44,2 & 43,2 & 42,3 \\
\hline Ensino fundamental completo & 6,3 & 4,2 & 4,0 \\
\hline Ensino médio completo (1) & 12,7 & 6,3 & 6,3 \\
\hline Superior & 8,0 & 0,7 & 0,7 \\
\hline \multicolumn{4}{|l|}{ Cor } \\
\hline Branca & 59,1 & 44,7 & 46,9 \\
\hline Preta & 6,7 & 8,6 & 10,2 \\
\hline Parda & 33,4 & 46,2 & 42,1 \\
\hline Demais & 0,8 & 0,5 & 0,8 \\
\hline \multicolumn{4}{|l|}{ Sexo } \\
\hline Homens & 40,4 & 37,5 & 30,5 \\
\hline Mulheres & 59,6 & 62,5 & 69,5 \\
\hline \multicolumn{4}{|l|}{ Posição na ocupação } \\
\hline Empregados com carteira & 6,0 & 2,4 & 0,0 \\
\hline Empregados sem carteira & 3,8 & 2,9 & 0,8 \\
\hline Conta-própria com previdência & 0,8 & 0,2 & 0,0 \\
\hline Conta-própria sem previdência & 9,9 & 8,5 & 1,2 \\
\hline Empregadores com previdência & 0,7 & 0,0 & 0,0 \\
\hline Empregadores sem previdência & 1,2 & 0,5 & 0,1 \\
\hline Domésticos com carteira & 0,5 & 0,5 & 0,0 \\
\hline Domésticos sem carteira & 1,9 & 2,3 & 1,5 \\
\hline Trab. não-remunerados (mais de 15 horas) & 7,5 & 10,4 & 7,7 \\
\hline \multicolumn{4}{|l|}{ Ramo de atividade } \\
\hline Agrícola & 12,6 & 16,0 & 7,7 \\
\hline Outras atividades industriais & 0,1 & 0,0 & 0,0 \\
\hline Indústria de transformação & 3,5 & 2,1 & 0,5 \\
\hline Indústria da construção & 1,0 & 0,5 & 0,1 \\
\hline Comércio e reparação & 4,2 & 2,4 & 0,4 \\
\hline Alojamento e alimentação & 1,2 & 0,9 & 0,3 \\
\hline Transporte e comunicação social & 1,0 & 0,4 & 0,0 \\
\hline Administração pública & 0,8 & 0,4 & 0,0 \\
\hline Serviços sociais & 2,6 & 0,9 & 0,2 \\
\hline Serviço doméstico & 2,4 & 2,8 & 1,5 \\
\hline Outros serviços & 1,3 & 0,9 & 0,6 \\
\hline Outras atividades maldefinidas & 1,6 & 0,4 & 0,0 \\
\hline
\end{tabular}

Fonte: IBGE. Pesquisa Nacional por Amostra de Domicílios - PNAD. Elaboração dos autores.

(1) Inclui as pessoas com ensino médio incompleto. 
aposentadoria revela que mais de $85 \%$ eram inativos, pouco mais de $6 \%$ estavam desempregados e cerca de $4 \%$ exerciam algum tipo de ocupação, em 2004. Quando se avalia a situação das famílias em geral, observa-se que somente cerca de $26 \%$ dos que recebiam algum tipo de benefício também tinham algum membro inserido no mercado de trabalho. Esta característica explica o fato de o impacto positivo das transferências de renda ser mais importante para as famílias de baixa renda do que para o total das famílias.

Dessa forma, conclui-se que, em geral, os componentes das famílias que recebem remuneração decorrente de transferências possuem características mais adequadas para complementarem tais benefícios com as rendas do trabalho, cuja origem é fundamentalmente de atividade agrícola e de inserções autônomas sem pagamento à previdência. Nota-se, entretanto, que o benefício previdenciário tende a ser superior à renda propiciada pelo mercado de trabalho, reiterando, portanto, a situação de insuficiência de renda destas famílias decorrente de sua inserção econômica.

Por outro lado, para reforçar este argumento, percebe-se que os componentes das famílias mais pobres que recebiam as transferências de renda possuíam características que dificultam enormemente seu acesso ao mercado de trabalho. Resumidamente, observa-se que cerca de $60 \%$ tinham mais de 65 anos e mais de $16 \%$ possuíam idade superior a 55 anos. Além disso, cerca de $90 \%$ não haviam completado o ensino fundamental e, o que é mais grave, mais da metade não possuía sequer um ano de escolaridade. Por fim, encontra-se uma elevada presença de mulheres nesse grupo - cerca de $70 \%$.

Uma questão sobre a dinâmica dessas famílias mais pobres merece destaque: entre os poucos beneficiários que se inserem no mercado de trabalho como ocupados, há uma forte presença na categoria "sem remuneração". Esse fato indica que, provavelmente, além de contribuírem para a renda familiar com seu benefício, eles ainda participam da vida familiar ajudando os membros da família que exercem algum tipo de atividade produtiva. Como visto anteriormente, são grandes as probabilidades de tais atividades serem exercidas de maneira informal.

\section{Alternativas para as famílias de baixa renda: mundo do trabalho versus previdência social}

A partir do exposto, deve-se, em primeiro lugar, salientar a importância de uma política de transferências de recursos para as pessoas que não exercem atividade produtiva, por razões alheias à sua vontade.

Em geral, defende-se a importância desta política para redução dos diferenciais de renda. No entanto, a realidade confirma que tais políticas, por garantirem uma massa de recursos, são fundamentais para a sobrevivência destas famílias, independentemente do impacto redistributivo.

Desde que o salário mínimo foi fixado como o piso de benefícios em respeito aos preceitos da Constituição de 1988, e toda vez que se fala em aumentar o salário mínimo, surge discussão sobre a necessidade ou não de se desvincular o valor do piso de benefício e de contribuição do mínimo legal. Por um lado, o governo alega incansavelmente que o salário mínimo tem seu aumento restringido por sua vinculação ao menor valor do benefício previdenciário (por questões de inviabilidade atuarial da previdência e de desequilíbrio das finanças públicas). Por outro, argumenta-se que desvincular o piso previdenciário do salário mínimo provocaria uma maior marginalização dos beneficiários da previdência social, em razão da maior parte deles vir a ser obrigada a sobreviver com uma renda inferior ao salário mínimo, já reconhecidamente insuficiente para cobrir as necessidades básicas das pessoas (ANFIP, 1995, p. 44; DAIN e MATIJASCIC, 2005, p. 71).

Também merece ser destacado que a desvinculação do benefício previdenciário ampliaria o volume de famílias e pessoas com renda per capita inferior a $1 / 4$ do salário mínimo, o que exigiria aumento dos gastos dos outros programas sociais do governo, em razão das determinações da Lei no $8.742 / 93$ 
Atualmente, há um conjunto importante de argumentos contrários à continuidade da vinculação do piso previdenciário e mesmo de outros benefícios sociais ao salário mínimo. Os argumentos são justificados na suposta necessidade de equilíbrio nas contas públicas e, em especial, da previdência social.

Em geral, os defensores desta tese argumentam que uma maior liberdade de fixação do salário no mercado de trabalho elevaria os rendimentos pagos a quem efetivamente contribui no processo de produção de riquezas na economia.

Esta tese desconsidera que, desde 1995, boa parte das remunerações é determinada por mecanismos endógenos ao mercado de trabalho, sendo que somente os empregados formais com renda próxima ao piso legal têm sua remuneração afetada pela política do salário mínimo. Ademais, a realidade mostra que, a despeito de um mínimo fixado, parcela ponderável de ocupados aufere renda inferior ao salário mínimo e que, além disso, os rendimentos médios vêm apresentando tendência de aproximação ao valor do piso legal. No caso das famílias de baixa renda, observa-se a recorrência de um rendimento do trabalho inferior ao salário mínimo. Isto é, os mecanismos de determinação salarial via mercado de trabalho não têm produzido o resultado esperado por aqueles que argumentam contra a política pública de valorização do salário mínimo.

Um segundo argumento, tão conservador quanto o anterior, mostra que os rendimentos oriundos de pensões e aposentadorias, por serem mais elevados e garantidos, teriam um impacto negativo no estímulo ao trabalho. Ou seja, o indivíduo, através de um cálculo racional, preferiria não trabalhar, pois teria sua velhice garantida pela política previdenciária do governo. Quanto a esta proposição, não seria razoável imaginar que esta seria uma ação calculada pelo trabalhador.
Ademais, os resultados deste ensaio mostram que a insuficiência de renda das famílias é produto da baixa remuneração auferira nas ocupações de base do mercado de trabalho e não de sua baixa participação econômica.

Como dito anteriormente, num cenário de pequeno crescimento econômico e com um mercado de trabalho cuja seleção de trabalhadores privilegia os mais jovens e mais escolarizados, há um desafio para ser enfrentado pelos componentes de famílias de baixa renda: encontrar meios de sobrevivência que os retire da situação de pobreza extrema a que estão condenados pela ausência de vagas no mercado de trabalho para pessoas com seu nível de qualificação.

Maia et alii (2005) confirmam que, na ausência do acesso ao benefício da previdência social, a população em situação de pobreza saltaria de 10 milhões para 25 milhões de pessoas. Ou seja, para os autores, a ausência da renda previdenciária igualaria as condições entre o primeiro e o segundo decil de distribuição de renda das famílias.

Em termos normativos, também pode ser encontrado respaldo para a política de transferência de renda. A Organização Internacional do Trabalho (OIT), em sua convenção n‥ 102, ${ }^{1}$ aprovada em Genebra em 1952, concebeu um conceito de Seguridade Social, que pautou a Constituição Federal de 1988 quanto à proteção social de responsabilidade dos poderes públicos. Segundo esse conceito, a importância de se ter um aparato de assistência social, aí incluindo, logicamente, a previdência social, está no entendimento de que a Seguridade Social é instrumento de transformação e progresso social, ao invés de constituir obstáculo ao progresso econômico.

Dentro de um modo capitalista e, portanto, excludente, de produção, "a Seguridade Social significa a proteção que a sociedade proporciona a seus membros". Além disso,

\footnotetext{
${ }^{1}$ Convenção no. 102 da OIT: "Seguridade Social é a proteção que a sociedade proporciona a seus membros, mediante uma série de medidas públicas contra as privações econômicas e sociais que, de outra forma, derivam do desaparecimento ou em forte redução de sua subsistência como conseqüência de enfermidade, maternidade, acidente de trabalho ou enfermidade profissional, desemprego, invalidez, velhice e também a proteção em forma de assistência médica e ajuda às famílias com filhos" (ANFIP, 1995, p. 31).
} 
significa "dar aos indivíduos e às famílias a tranqüilidade de saber que o nível e a qualidade de sua vida não serão significativamente diminuídos, até onde for possível evitálo, por nenhuma circunstância econômica ou social" (ANFIP, 1995, p. 31-32).

\section{Considerações finais}

O exercício analítico desenvolvido neste trabalho confirma que a previdência social vem sendo um mecanismo relevante para superação da precariedade da situação socioeconômica das famílias de baixa renda e, portanto, da situação de pobreza extrema. No entanto, a questão que se coloca é sobre a viabilidade de adoção desta solução a médio e longo prazos.

Pode-se levantar um conjunto de argumentos humanitários incontestáveis para a continuidade da política de transferência de recursos para os grupos sociais menos favorecidos. No entanto, há certa fragilidade em alguns deles pautados em questões éticas, visto que podem facilmente ser refutados, dependendo da valoração moral que a sociedade conceda a eles.

Talvez o caminho em defesa de uma política de manutenção dos benefícios deva ser encontrado na própria dinâmica de funcionamento da economia. Isto significa levantar a possibilidade de a política previdenciária ser vista da mesma maneira que as políticas de custeio, cuja finalidade seria minimizar, ou, pelo menos, manter num patamar mínimo a categoria de consumo das famílias. Este fato, como amplamente aprendido nos manuais de economia, além de reduzir as oscilações de demanda, poderia até gerar uma fonte maior de receita, em forma de tributos, para o Estado.

Contudo, a análise da condição de renda das famílias mais pobres mostra claramente que a redução da sua dependência da política social depende da melhoria das condições do crescimento econômico, naquilo que se refere à sua capacidade de ampliar significativamente o volume de novas oportunidades de ocupação no mercado nacional de trabalho.

A elevação do nível de escolaridade é uma debilidade da inserção econômica das famílias de baixa renda que deve ser atacada com extrema prioridade pela política pública. Porém, o melhor perfil educacional somente será eficiente econômica e socialmente se forem criados novos postos de trabalho em volume que permita a redução da fila.

A menor disputa pelos baixos postos de trabalho disponíveis é fundamental para as famílias de baixa renda, mesmo que seu perfil educacional seja alterado. Afinal, estas continuarão a ter nas ocupações de base do mercado de trabalho seu espaço de inserção, as quais dependem fundamentalmente do crescimento para melhorarem seus níveis de renda.

Portanto, a menor dependência das famílias de baixa renda da política social depende do crescimento econômico e de seus efeitos dinâmicos sobre o mercado de trabalho. Sem dúvida, políticas públicas de educação e qualificação poderão contribuir para a virtuose deste movimento, apesar de não serem capazes de resolver os problemas de emprego que estas famílias enfrentam.

As políticas sociais são, portanto, instrumentos necessários e eficientes para a proteção social das famílias de baixa renda, apesar desta condição social estruturalmente desfavorável poder somente ser modificada por um crescimento econômico que dinamize fortemente o mercado de trabalho.

Em face das condições atuais prevalecentes no mercado de trabalho, a política social cumpre papel decisivo na sustentação do atual poder de compra das famílias de baixa renda, como, ademais, o salário mínimo tem importância decisiva para sua evolução. Conclui-se, portanto, que a política de valorização do salário mínimo cumpre papel decisivo para as famílias de baixa renda, através da proteção social e não por meio do mercado de trabalho. Para que esta tenha maior efetividade através do mercado de trabalho e permita uma menor relevância via política de previdência, é necessário que se restabeleça uma trajetória de crescimento sustentado que crie uma capacidade recorrente e respeitável de criação de novos postos de trabalho, em ritmo muito superior ao incremento natural da população eco- 
nomicamente ativa. Isto é, que se facilite a entrada no mercado de trabalho dos membros das famílias de baixa renda, inclusive com níveis de remuneração mais favoráveis.

\section{Referências bibliográficas}

ANFIP - Associação Nacional dos Auditores Fiscais da Previdência Social. Um fórum para a Seguridade Social: saúde, assistência e previdência social. Brasília: Anfip, 1995. 143 p.

BALTAR, P. Salário mínimo e mercado de trabalho. In: BALTAR, P. et alii (Orgs.). Salário mínimo e desenvolvimento. Campinas: Instituto de Economia/Unicamp, 2005, p.41-48

BARBIERI, C. V. Análise metodológica dos indicadores de pobreza. TCC - Instituto de
Somente deste modo poderá se reduzir o papel da previdência social para as famílias de baixa renda, sem incorrer em perda da proteção social limitadamente hoje existente.

Economia/ Unicamp. Campinas: Instituto de Economia/Unicamp, nov. 2003. 43 p.

DAIN, S.; MATIJASCIC, M. Finanças públicas, salário mínimo e seguridade social: as aparências enganam. In: BALTAR, P. et alii (Orgs.). Salário mínimo e desenvolvimento. Campinas: Instituto de Economia/ Unicamp, 2005, p. 71-90.

MAIA, A. G. et alii. A contribuição da aposentadoria para a distribuição de renda. Apresentado na Anpec, 2005. 19 p.

\begin{abstract}
Minimum wage, social security benefits and low-income families

This article discusses families with per capita income of up to $1 / 4$ of the minimum monthly wage in Brazil. The conditions of participation in the labor market and the influence of social security benefits on the pattern of income earned are analyzed. The concern, therefore, is with the importance of social security benefits in attenuating the fragility of the income of these families and the consequences of the gap between their income and the minimum wage for this pattern of income. Characteristics of the members of low-income families showed that, in view of the structural changes in the production process and the current juncture of the Brazilian economy, persons of active working age lack the pre-requisites for participating with dignity in the world of labor. A study of the composition of the income of the poorest families shows that the income of inactive members (retired persons and pension receivers) is essential in preventing these families from falling below the poverty line. The profile of the members of such families is analyzed on the basis of microdata from the National Household Survey by Sample (PNAD/ IBGE) of 2004, according to age, educational level, color or ethnic group, and participation in the labor market, strictly speaking. Factors studied include the type of work exercised and the position in the occupation. The comparison of the profile of members of the poorest families with that of all families shows that the income of retired members and pension receivers are essential not only in reducing the fall in inequality, but basically in reducing poverty itself.
\end{abstract}

Key words: Minimum wage. Social security. Low-income families. Transfer of income.

Recebido para publicação em 29/09/2006. Aceito para publicação em 06/11/2006. 
